\title{
PCDD/F removal at low temperatures over Vanadium-based catalyst: insight into the superiority of mechanochemical method
}

\section{Minghui Tang}

Zhejiang University

\section{Qiulin Ye}

Zhejiang University

Cuicui Du

Zhejiang University

\section{Yaqi Peng}

Zhejiang University

\section{Chengetai Portia Makwarimba}

Zhejiang University

Yao He

POWERCHINA Central China Electric Power Engineering Co., Ltd.

Shengyong Lu ( $\nabla$ lushy@zju.edu.cn )

Zhejiang University https://orcid.org/0000-0003-2684-3498

\section{Research Article}

Keywords: PCDD/F removal, PCDD/F catalytic degradation, 1,2-DCBz, VOx/TiO2 catalyst, mechanochemical, ball-milling parameters

Posted Date: May 13th, 2021

DOI: https://doi.org/10.21203/rs.3.rs-463575/v1

License: (c) (1) This work is licensed under a Creative Commons Attribution 4.0 International License. Read Full License

Version of Record: A version of this preprint was published at Environmental Science and Pollution Research on August 31st, 2021. See the published version at https://doi.org/10.1007/s11356-021-15477y. 


\section{Abstract}

The high toxicity and low volatility of PCDD/Fs prevent detailed study of their catalytic degradation removal characteristics. In this study, firstly, 1,2-dichlorobenzene (1,2-DCBz) was initially used as a model to investigate the catalytic characteristics of various vanadium-based catalysts prepared by different methods. Then, the optimized catalyst was used for catalytic degradation of real PCDD/Fs at low-

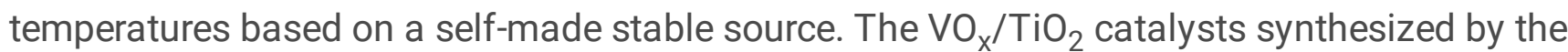
mechanochemical method (VTi-MC2) had a higher 1,2-DCBz removal efficiency (> 85\%) and stability (> $420 \mathrm{~min}$ ) at low temperatures $\left(<200^{\circ} \mathrm{C}\right.$ ) compared to VTi-SG (sol-gol method) and VTi-WI (wetness impregnation method). The physico-chemical properties of catalysts were studied using comprehensive characterization. It was found that the VTi-MC2 has better $\mathrm{VO}_{\mathrm{x}}$ species distribution and possesses the highest $\mathrm{V}^{5+}$ species and surface adsorbed oxygen content, which are the key factors contributed to the higher removal efficiency. Accordingly, the mechanochemical method can be used to control the physicochemical properties of catalyst by adjusting the milling parameters. The optimum ball-milling time is $2 \mathrm{~h}$ and the suitable precursor is $\mathrm{NH}_{4} \mathrm{VO}_{3}$ for $\mathrm{VO}_{\mathrm{x}} / \mathrm{TiO}_{2}$. Moreover, the removal efficiency of gas phase PCDD/Fs catalyzed by VTi-MC2 is $97 \%$ within a temperature range below $200{ }^{\circ} \mathrm{C}$, and the catalytic degradation of PCDD/Fs surges to $50 \%$, which is higher than those reported research. In general, the mechanochemical strategy reported provides a means for seeking more efficient catalysts used for lowtemperature degradation of various trace organic pollutants.

\section{Introduction:}

The emission control of polychlorinated dibenzo-p-dioxins (PCDDs) and polychlorinated dibenzofurans (PCDFs) in incineration flue gas has aroused widespread attention in recent years. Although the emissions of PCDD/Fs species are trace, their extreme toxicity and very low volatility tend to cause massive damage to the bio-system. Hence, the PCDD/Fs are listed as Persistent Organic Pollutants (POPs) in the Stockholm Convention on Persistent Organic Pollutants (POPs) (Yang et al. 1999). Particularly, with the implementation of more stringent standards for dioxin emissions from incinerators, it is urgent to develop and improve the control technology. Usually, model compounds, such as chlorobenzenes, chlorophenols, or furans are used in the research of catalytic decomposition of dioxins(Bertinchamps et al. 2005, Chin et al. 2009, Wang et al. 2015). They have a similar structure to dioxins, yet are easier and safer to handle. Further, these compounds also exist in MSWI flue gas (Everaert \&Baeyens 2002, Oh et al. 2021) and are possible precursors in the dioxin formation process(Cieplik et al. 2006, McKay 2002).

Compared with the commonly used adsorption technology, catalytic degradation technology can completely decompose dioxins without causing secondary pollution, which is considered as a potential terminal control technology(Yu et al. 2016). Vanadium-based catalysts are especially acknowledged in the study of catalytic degradation of dioxin and dioxin-like compounds due to their potentially high oxidation activities and excellent resistance against chlorine poisoning.(Bertinchamps et al. 2006, 
Delaigle et al. 2009a) However, the active temperature of common vanadium-based catalysts for PCDD/Fs degradation $\left(200-350^{\circ} \mathrm{C}\right)$ is higher than the temperature of the flue gas section in the installed catalytic unit (generally $<200^{\circ} \mathrm{C}$ )(Chang et al. 2007, Du et al. 2018b). Thus, preparing a more efficient and environmentally friendly catalyst that can be used under low temperature conditions for the removal of PCDD/Fs is urgently needed.

Due to the trace concentrations, low volatility and extreme toxicity of dioxins, it is difficult for general researchers to generate a stable gaseous dioxin and control its concentration under laboratory conditions. This, hinders the study of its catalytic removal mechanism. Some researchers used lowtoxicity dioxin model compounds to replace gaseous dioxins for research.

M. Gallastegi-Villa has studied a $\mathrm{VO}_{\mathrm{x}} / \mathrm{TiO}_{2}$ catalyst prepared by wet impregnation for the catalytic removal of $\mathrm{NO}_{x}$ with 1,2-DCB as the model PCDD/Fs compound (Gallastegi-Villa et al. 2017, GallastegiVilla et al. 2020). And the results showed that when the temperature was below $200^{\circ} \mathrm{C}$, the removal efficiency of 1,2-DCB was less than $20 \%$. Wang adopted the sol-gel method to prepare $\mathrm{VO}_{\mathrm{x}} / \mathrm{TiO}_{2}$, and the degradation efficiency of PCDD/Fs at $220^{\circ} \mathrm{C}$ only reached $26.7 \%$ (Wang et al. 2016). Debecker has evaluated vanadium-based catalysts prepared by a classical wet impregnation for the removal of $\mathrm{PCDD} /$ Fs. Although the $\mathrm{VO}_{\mathrm{x}} / \mathrm{TiO}_{2}$ catalysts exhibit rather good removal efficiencies (about $92 \%$ ) at 200 ${ }^{\circ} \mathrm{C}$, unfortunately, the degradation efficiency is unclear (Debecker et al. 2011).

Recently, there has been an increasing interest in the mechanochemical synthesis of heterogeneous catalysts. Compared with the traditional catalyst synthesis method, such as the sol-gel method (SG) and wetness impregnation method (WI), the mechanochemical method (MC) has widely gained attention due to its simple operation and low cost (Baláž et al. 2013, Ralphs et al. 2013). In particular, the attention to the environmental problems caused by the use of solvents makes the study of the mechanization method very urgent (James et al. 2012). During the mechanochemical synthesis, the energy generated in the grinding process can have several positive effects on the catalyst, such as generating crystal defects, reducing the particle size, promoting dispersion of active species, forming new interface, and amorphous transformation (Danielis et al. 2019, Kwon et al. 2013, Muñoz-Batista et al. 2018).

To date, several heterogeneous catalysts have been prepared successfully through the mechanochemical method and used for gaseous POPs removal(Yang et al. 2015, Zhang et al. 2015). Whereas, to the best of our knowledge, few studies have reported the application for removal trace organic contaminants in exhaust gas, especially real dioxins or dioxin-like compounds. Furthermore, the variable ball-milling parameters and mechano-chemical effects affect the application for catalytic degradation.

Therefore, in this paper, mechanochemical method was applied to prepare $\mathrm{VO}_{\mathrm{x}} / \mathrm{TiO}_{2}$ catalysts, and the catalytic removal performance of dioxin model compounds 1,2-DCBz as well as dioxins under low temperature conditions were evaluated. It is verified that the $\mathrm{VO}_{\mathrm{x}} / \mathrm{TiO}_{2}$ catalyst prepared by a novel solvent-free mechanochemical method display excellent catalytic activity in comparison with catalysts prepared by the conventional wetness impregnation (WI) method and sol-gel (SG) method. Furthermore, 
comprehensive characterization techniques were performed to study the physico-chemical properties of catalysts to explore the advantage of the mechanochemical method. The effects of precursors and the ball-milling time on catalyst performances were also investigated.

\section{Experimental Section}

\subsection{Catalyst preparation}

Ammonium metavanadate $\left(\mathrm{NH}_{4} \mathrm{VO}_{3}\right)$, vanadium oxide $\left(\mathrm{V}_{2} \mathrm{O}_{5}\right)$, tetrabutyl titanate $\left(\mathrm{C}_{16} \mathrm{H}_{36} \mathrm{O}{ }_{4} \mathrm{Ti}\right)$, oxalic acid, ethanol, 1,2-dichlorobenzene were purchased from Sinopharm Chemical Reagent Co., China. Nano$\mathrm{TiO}_{2}$ powder was bought from Xuanchengjingrui New Material Co., Ltd., China.

A series of $\mathrm{VO}_{x} / \mathrm{TiO}_{2}$ catalysts were synthesized by a mechanochemical method. The milling process was performed in a Planetary Ball Mill (QXQM-2I, Changsha TENCAN Powder Technology Co., Ltd, China) with four steel jars $(250 \mathrm{~mL})$. In a typical synthesis process of $\mathrm{VO}_{\mathrm{x}} / \mathrm{TiO}_{2}$, a mixture of $\mathrm{NH}_{4} \mathrm{VO}_{3}$ and nano- $\mathrm{TiO}_{2}$ powders (based on 5 at\% vanadium) were physically mixed together thoroughly. Then, the mixture was put into a stainless steel milling pot with several steel balls. The diameters of the steel balls were $10 \mathrm{~mm}$ and $5 \mathrm{~mm}$ with weight ratios of 1:1. The weight ratio of mixture and steel balls was 20:1. The milling speed of the Planetary Ball Mill was set as $550 \mathrm{rpm}$. After ball-milling for a certain period of time $(0.5 \mathrm{~h} \sim$ $4 \mathrm{~h}$ ), the resultant sample was obtained after the powder was calcined at $450^{\circ} \mathrm{C}$ for $3 \mathrm{~h}$ in air, which was denoted as VTi-MCt (t: ball-milling time). In order to explore the influence of a vanadium precursor, the VTi-MC* was prepared through the same process with $\mathrm{V}_{2} \mathrm{O}_{5}$ powder as the precursor.

For comparison, $\mathrm{VO}_{\mathrm{x}} / \mathrm{TiO}_{2}$ was also prepared through the conventional wetness impregnation method $(\mathrm{WI})$ and sol-gel method (SG) respectively.

Appropriate amounts of $\mathrm{NH}_{4} \mathrm{VO}_{3}$ and oxalic acid (molar ratio 2:1) were dispersed in deionized water at 60 ${ }^{\circ} \mathrm{C}$ under vigorous stirring to form a dark-blue solution. The desired amounts of $\mathrm{Nano}^{-\mathrm{TiO}_{2}}$ powder was then added to the solution and stirred for $0.5 \mathrm{~h}$. After standing in air for $24 \mathrm{~h}$, the mixture was dried at 105 ${ }^{\circ} \mathrm{C}$ for $12 \mathrm{~h}$ and then crushed to 100 mesh powder. The obtained catalyst was calcined in a muffle furnace for $3 \mathrm{~h}$ at $450^{\circ} \mathrm{C}$, which was denoted as VTi-WI.

$\mathrm{C} 16 \mathrm{H} 3604 \mathrm{Ti}(0.2 \mathrm{~mol})$ and acetic acid $(40 \mathrm{~mL})$ were dissolved in ethanol $(150 \mathrm{~mL})$, and stirred for $30 \mathrm{~min}$ to form a suspension. $\mathrm{NH}_{4} \mathrm{VO}_{3}(1.8 \mathrm{~g})$ was dissolved in deionized water $(25 \mathrm{~mL})$ with the addition of oxalic acid $(5.8 \mathrm{~g})$ to form a settled orange-yellow solution. Then, it was added to the former suspension dropwise under stirring until a homogenous gel was formed. The resulting gel was standing at room temperature for $24 \mathrm{~h}$, dried at $105^{\circ} \mathrm{C}$ for $12 \mathrm{~h}$, and then crushed to fine powder. Finally, the resulting catalyst sample was calcined at $450^{\circ} \mathrm{C}$ for $3 \mathrm{~h}$, which was denoted as VTi-SG.

\subsection{Catalyst Characterization}


The Scanning electron microscope (SEM) analysis was performed on a Hitachi S-4800 electron microscope. The BET specific surface areas and pore distribution were measured on a surface area and porosity analyzer (TRISTAR 3020,Micromeritics Instrument CorpLUSA). Temperature-programmed desorption of ammonia (NH3-TPD) was conducted on a Xianquan TP-5080 (TP 5080, Xianquan Instrument Corp, China) equipped with a thermal conductivity detector (TCD). X-ray power diffraction analysis (XRD) was performed using PANalytical-X'Pert PRO, Holland. The X-ray photoelectron spectra (XPS) were obtained by an ESCALAB MARK II spherical analyzer using an aluminum-magnesium binode (Al $1486.6 \mathrm{eV}, \mathrm{Mg} 1253.6 \mathrm{eV}$ ) X-ray source. All binding energies were corrected with the reference to the $\mathrm{C}$ $1 \mathrm{~s}$ line at $284.8 \mathrm{eV}$. Hydrogen temperature-programmed reduction $\left(\mathrm{H}_{2}-\mathrm{TPR}\right)$ was conducted in Micromeritics Autochem $\triangle 2920$ apparatus equipped with a TCD detector. Before a TPR run, catalysts were pretreated in $\mathrm{Ar}$ at $473 \mathrm{~K}$ for 2 hours. TPR was performed in a flow of $10 \% \mathrm{H}_{2} /$ Ar mixture gas at a flow rate of $10 \mathrm{sccm}$ with a temperature ramp of $10^{\circ} \mathrm{C} / \mathrm{min}$ from 50 to $800^{\circ} \mathrm{C}$.

\subsection{Activity test}

To evaluated the catalytic properties of the catalysts for 1,2-DCBz, the experiment was conducted in a fixed-bed flow device with a quartz tube (inner diameter, $33 \mathrm{~mm}$ ) as the reactor (Figure S1). An appropriate amount of catalysts was placed at the middle of the quartz tube, and fixed by quartz wool. The 1,2-DCBz steam was generated by the bubbling method and $\mathrm{N}_{2}$ was used as the carrier gas. The gas stream replenished into the reactor adopted $11 \% \mathrm{O}_{2}$ and $89 \% \mathrm{~N}_{2}$ as a diluting gas, and was controlled by a mass flow controller (designated as $1,2-\mathrm{DCBz}_{\text {inlet }}$ ). Residual $1,2-\mathrm{DCBz}$ in the effluent gas was collected by ethanol (designated as $1,2-\mathrm{DCBz}_{\text {outlet }}$ ), and analyzed using a chromatographer (Agilent $6890 \mathrm{~N}$ ) with a 30 m column (DB-5) and an electron capture detector. The removal efficiency (RE) was calculated as follows:

$\mathrm{RE}(\%)=\left(1,2-\mathrm{DCBz}_{\text {inlet }}-1,2-\mathrm{DCBz}_{\text {outlet }}\right) / 1,2-\mathrm{DCBz}_{\text {inlet }} \times 100 \%(1)$

The catalytic degradation of gaseous $\mathrm{PCDD} / \mathrm{Fs}$ over $\mathrm{VO}_{\mathrm{x}} / \mathrm{TiO}_{2}$ catalysts were conducted in a self-made device as shown in Figure S2. A stable dioxin gas generator (Du et al. 2018a) was employed to supply stable gaseous PCDD/Fs and the initial concentration of gaseous PCDD/Fs (PCDD/Fsinlet) was detected as $3.20 \mathrm{ng}$ I-TEQ/ $/ \mathrm{Nm}^{3}$ (averge value of three runs, with a standard deviation of $6.8 \%$, as is shown in Table S1). An appropriate amount of the catalyst was loaded into the quartz tube, and fixed by quartz wool and a quartz screen. A gas mixture of $11 \mathrm{vol}^{\mathrm{O}} \mathrm{O}_{2}$ and $\mathrm{N}_{2}$ (balance) was used as the carrier gas. The total gas flow passing through the reactor was set at $500 \mathrm{ml} / \mathrm{min}$ by a mass flow controller (GHSV $=14000 \mathrm{~h}-1$ ).

The test system was kept for 60 min in advance to reach a steady state before taking samples. Then, the vapor phase PCDD/Fs in effluent gas were continuously collected by XAD-2 resin and toluene for 60 min $\left(\mathrm{PCDD} / \mathrm{Fs}_{\text {outlet }}\right)$. After each experimental run, the glass tube and the used catalyst were rinsed and Soxhlet was extracted with toluene for the determination of residual PCDD/Fs on the catalyst surface and reactor inner walls (PCDD/Fson-catalyst). The quantitative detection of PCDD/Fs followed the US EPA method 1613 (US EPA, 1994). In our experiments, the recovery rate of each internal standard ranged from $62-107 \%$ and fulfilled the recovery standard of $40-130 \%$. 
Only the 17 toxic PCDD/Fs congeners were discussed in this work. The Removal Efficiency (RE), Degradation Efficiency (DE) and Adsorption Efficiency (AE) are defined as follows:

$\mathrm{RE}(\%)=\left[\mathrm{PCDD} / \mathrm{Fs}_{\text {inlet }}-\mathrm{PCDD} / \mathrm{Fs}_{\text {outlet }}\right] / \mathrm{PCDD} / \mathrm{Fs}_{\text {inlet }} \times 100(1)$

$D E(\%)=\left[P C D D / F s_{\text {inlet }}-P C D D / F s_{\text {outlet }}-P C D D / F s_{\text {on-catalyst }}\right] / P C D D / F s_{\text {inlet }} \times 100$ (2)

$\mathrm{AE}(\%)=\mathrm{PCDD} / \mathrm{Fs}_{\text {on-catalyst }} / \mathrm{PCDD} / \mathrm{Fs}_{\text {inlet }} \times 100(3)$

In which, PCDD/Fs inlet $_{\text {is }}$ the initial PCDD/Fs I-TEQ concentration; PCDD/Fs outlet presents the PCDD/Fs ITEQ concentration in the off-gas collected by XAD-2 polymeric resin and toluene; PCDD/Fs on-catalyst $_{\text {int }}$ signifies the PCDD/Fs I-TEQ concentration adsorbed on the catalyst surface and the reactor inner walls.

\section{Results And Discussion}

\subsection{Catalyst characterization}

The microstructure of various $\mathrm{VO}_{\mathrm{x}} / \mathrm{TiO}_{2}$ catalysts were first identified by SEM (Fig. 1). It revealed that the VTi-MC sample was loosely accumulated with flaky particles, VTi-WI was contained with randomly spherical particles, and VTi-SG was presented by block morphology without apparent stacked particles. It clearly shows that different preparation methods have influence on the microstructure of the catalyst samples.

The porosity of various samples was then characterized by nitrogen adsorption-desorption isothermal analysis. Figure $\mathrm{S} 3(\mathrm{~A})$ illustrates that the $\mathrm{N}_{2}$ adsorption-desorption isotherms of the catalysts prepared by three different methods are all typical Type $I V$ isotherms, which indicates that these catalyst samples have mesoporous structures(K. S. W. SING \&R. A. PIEROTTI 1985). Intriguingly, the hysteresis loops of the three catalysts present a wide variety of shapes, indicating that three catalysts have different specific pore structures. The isothermal curve of the VTi-MC catalyst shows Type H3 hysteresis loop, demonstrating that the pore structure of the catalyst is slit-shaped and formed by loose accumulation of plate-like particles. The isothermal curve of the VTi-WI catalyst displays a Type H1 hysteresis loop. This implies that the pore structure of the catalyst consists of agglomerates or compacts of approximately uniform spherical particles in fairly regular array. The isothermal curve of the VTi-SG catalyst exhibits a Type $\mathrm{H} 2$ hysteresis loop, which is a representation of narrow necks and wide bodies pores ('ink bottle' pores) or fine particle accumulation pores in the catalyst. Overall, the nitrogen adsorption-desorption isothermal is in accordance with the SEM results.

What's more, according to Figure S3(B), the pore size distribution of VTi-MC and VTi-SG is concentrated in the range of $3-8 \mathrm{~nm}$, while that of VTi-WI is concentrated in the range of $10-45 \mathrm{~nm}$. Furthermore, the specific surface areas decrease in the order of VTi-SG $\left(133 \mathrm{~m}^{2} / \mathrm{g}\right)>\mathrm{V} / \mathrm{Ti}-\mathrm{MC}\left(86 \mathrm{~m}^{2} / \mathrm{g}\right)>\mathrm{VTi}-\mathrm{WI}(44$ $\mathrm{m}^{2} / \mathrm{g}$ ). Furthermore, VTi-SG and VTi-MC have equally higher acidity than VTi-WI. 
It is worth noting that the mechanochemical parameters have obvious influence on the physicochemical properties of the VTi-MCt catalysts. Initially, with the increase of ball milling time, the specific surface area of catalyst increases at first and then decreases. When the ball milling time is $2 \mathrm{~h}$, the specific surface area reaches a maximum value of $86 \mathrm{~m}^{2} / \mathrm{g}$. This may be ascribed to the energy generated during ball milling process promoting the formation of a new interface in the catalyst (Ralphs et al. 2013). However, further increasing the milling time to $4 \mathrm{~h}$ results in a sharp decrease, possibly owing to the structure collapse. This was confirmed by the following XRD characterization. Previous studies demonstrated that pores of 2-5 nm diameter are in favour of the adsorption of 1,2-DCBz and dioxins(Xujian et al. 2014). According to Figure S3(C), the pore volumes of 2-5 nm diameter rise with the increase of milling time, reach a maximum when the milling time is $2 \mathrm{~h}$, and then decrease as a result of a pore structure collapse.

Similar tendency is also observed on the acidity of these catalysts. As reported by Delaigle, $\mathrm{VO}_{x}$ presents a lot of Brønsted acid sites while the support $\mathrm{TiO}_{2}$ mainly exhibits Lewis acid sites and only has a small number of Brønsted acid sites (Delaigle et al. 2009b). Therefore, better dispersion of $\mathrm{VO}_{x}$ as the milling time increases brings more Brønsted acid sites. However, too long milling time ( $\geq 4 \mathrm{~h}$ ) can cause a collapse of $\mathrm{TiO}_{2}$ crystal structures, resulting in a sharp decrease of Lewis acid sites of catalysts.

Vanadium precursors also have significant effects on the specific surface area and pore structure of the catalysts. In order to compare the results of the VTI-MC2 which used $\mathrm{NH}_{4} \mathrm{VO}_{3}$ as a precursor, $\mathrm{V}_{2} \mathrm{O}_{5}$ was selected as a precursor and VTI-MC2* was prepared through the same method. As shown in Table 1, the specific surface area of the VTI-MC2 was more than 3 times higher than that of VTI-MC2*. The total pore volume of VTI-MC2 was about 2 times higher than that of VTI-MC2*. Normally, due to the energy produced during grinding process, $\mathrm{NH} 4 \mathrm{VO} 3$ can decomposed to generate gaseous water and ammonia, which are beneficial to the formation of a well-developed pore structure of the catalyst. This promotes the interaction between vanadium oxide products and support $\mathrm{TiO}_{2}$, and thus forming a $\mathrm{VO}_{\mathrm{x}}$ supported catalyst. Therefore, the VTi-MC2 catalyst has a larger specific surface area and pore volume. Moreover, the pore volume and total acid content of the VTI-MC2 catalyst in the pore size range of $2-5 \mathrm{~nm}$ is significantly higher than that of VTI-MC2*, which is more conducive to the adsorption of 1,2dichlorobenzene on the surface of the catalyst.

The above results apparently show that the preparation methods and mechanochemical parameters have great influence on specific surface areas, porosity and acidity of catalysts. This observation inspires us to further investigate their effects on the physicochemical properties of catalysts in detail. 
Table 1

Specifications of the various carbon samples

\begin{tabular}{|lllll|}
\hline Material & $\begin{array}{l}\mathrm{S}_{\text {BET }} \\
\left(\mathbf{m}^{2} \mathbf{g} \mathbf{g}\right)\end{array}$ & $\begin{array}{l}\text { Pore volume } \\
\left(\mathbf{c m}^{3} / \mathbf{g}\right)\end{array}$ & Pore size(nm) & $\begin{array}{l}\text { total acid content } \\
(\mathbf{m m o l} / \mathbf{g})\end{array}$ \\
\hline VTi-SG & 133 & 0.19 & 5.4 & 0.374 \\
\hline VTi-WI & 44 & 0.26 & 26.5 & 0.088 \\
\hline VTi-MC0.5 & 38 & 0.09 & 12.6 & 0.075 \\
\hline VTi-MC1 & 40 & 0.10 & 11.3 & 0.077 \\
\hline VTi-MC1.5 & 50 & 0.14 & 11.1 & 0.084 \\
\hline VTi-MC2 & 86 & 0.19 & 8.0 & 0.344 \\
\hline VTi-MC3 & 57 & 0.15 & 11.8 & 0.080 \\
\hline VTi-MC4 & 31 & 0.08 & 12.5 & 0.046 \\
\hline VTi-MC2* & 27 & 0.10 & 16.3 & 0.102 \\
\hline * Derived from NH $_{3}$-TPD. & & \\
\hline
\end{tabular}

XRD was used to study the crystal structure of various catalyst samples. Figure S4 (A) shows the XRD patterns of VTi-WI, VTi-SG and various VTi-MCt catalysts. The diffraction peaks of VTi-WI and VTi-SG could be well indexed to anatase $\mathrm{TiO}_{2}$ (JCPDS 21-1272) (Zhang et al. 2015), and no characteristic peaks of $\mathrm{V}_{2} \mathrm{O}_{5}$ can be fitted. This indicates that the vanadium oxide species are well dispersed on the support amorphously or the microcrystals are less than $4 \mathrm{~nm}$ cannot be detected through the XRD(Gannoun et al. 2014).

Moreover, in comparison with VTi-WI and VTi-SG, VTI-MCt catalysts have relatively low intensity of $\mathrm{TiO}_{2}$ peaks, indicating that the ball milling process may lead to the structure defect of nano- $\mathrm{TiO}_{2}$. The increased crystal defects can serve as additional binding sites for VOx, which is beneficial to improve the dispersibility of the active component $\mathrm{VO}_{\mathrm{x}}$. Both anatase $\mathrm{TiO}_{2}$ and rutile $\mathrm{TiO}_{2}$ are present in all the catalysts synthesized by ball milling methods. Anatase $\mathrm{TiO}_{2}$ has a metastable phase structure, which is easily transformed into rutile $\mathrm{TiO}_{2}$ due to the milling effect(Coste et al. 2007). In particular, the diffraction peak intensity of rutile $\mathrm{TiO}_{2}$ firstly decreases with the increase of milling time $(0.5 \mathrm{~h} \sim 1.5 \mathrm{~h})$, disappeares at $2 \mathrm{~h}$, then reappeares at $3 \mathrm{~h}$, and increases with prolonging the ball milling time. Meanwhile, the diffraction peak intensity of anatase phase $\mathrm{TiO}_{2}$ gradually decreased, indicating that the anatase $\mathrm{TiO}_{2}$ converted into rutile phase during ball milling processes.

More importantly, the ball milling time also has an important effect on the dispersion of the active component VOx. When the ball-milling time increased from $0.5 \mathrm{~h}$ to $1.5 \mathrm{~h}$, the diffraction peak intensity of 
the $\mathrm{V}_{2} \mathrm{O}_{5}$ crystal decreased, indicating that the $\mathrm{V}_{2} \mathrm{O}_{5}$ crystal gradually transformed into microcrystalline or amorphous VOx. However, when the ball-milling time reached $2 \mathrm{~h}$ and $3 \mathrm{~h}$, the $\mathrm{V}_{2} \mathrm{O}_{5}$ crystal peak disappeared, indicating that the VOx on the catalyst surface is amorphous or the crystal particle sizes are small, which is lower than the detection limitation of XRD.This is consisteng with the study of Kwon et al., that the content of highly active monomeric VOx species increased with longer ball milling time (Kwon et al. 2013). But surprisingly, when the grinding time continuously increased to $4 \mathrm{~h}$, the diffraction peak of the $\mathrm{V}_{2} \mathrm{O}_{5}$ crystal with low intensity could be observed in the XRD pattern. This phenomenon may be ascribed to the extensively long ball milling time caused collapse of the crystal structure of $\mathrm{TiO}_{2}$. The collapse of the crystal structure is not conducive to the dispersion of $\mathrm{VO}_{\mathrm{x}}$ on the surface of $\mathrm{TiO}_{2}$, and the result is also in accordance with the $\mathrm{S}_{\mathrm{BET}}$ and pore volume.

Therefore, according to the results, it is reasonably to speculate that the formation process of $\mathrm{VO}_{\mathrm{x}}$ on the surface of the catalyst support during the ball milling process, $\mathrm{NH}_{4} \mathrm{VO}_{3}$ thermally decomposes to generate $\mathrm{V}_{2} \mathrm{O}_{5}$ crystals, and then transform into amorphous $\mathrm{VO}_{\mathrm{x}}$.

Figure S4(B) shows that obvious $\mathrm{V}_{2} \mathrm{O}_{5}$ crystals can be observed on the surface of the VTi-MC2* catalyst prepared with $\mathrm{V}_{2} \mathrm{O}_{5}$ powder as the precursor, indicating that the dispersion of the active component on the surface of $\mathrm{TiO}_{2}$ support is poor. According to the literature reports(Kwon et al. 2013), the synthesis of $\mathrm{V}_{2} \mathrm{O}_{5}$ powder and $\mathrm{TiO}_{2}$ occurred up to a milling time until $3 \mathrm{~h}$. This may be due to the fact that compared to $\mathrm{V}_{2} \mathrm{O}_{5}$ powder, the interaction between intermediate produced during ball milling of $\mathrm{NH}_{4} \mathrm{VO}_{3}$ (such as $\left.\left(\mathrm{NH}_{4}\right)_{2} \mathrm{O} \cdot 3 \mathrm{~V}_{2} \mathrm{O}_{5},\left(\mathrm{NH}_{4}\right)_{2} \mathrm{O} \cdot \mathrm{V}_{2} \mathrm{O}_{4} \cdot 5 \mathrm{~V}_{2} \mathrm{O}_{5}\right)$ and $\mathrm{TiO}_{2}$ is stronger, and it is easier to disperse on the surface of $\mathrm{TiO}_{2}$.

To get further insight into the chemical state of the catalysts surface element, XPS investigations were then conducted. Figure 2(a) shows the overlapping $\vee 2 p 3 / 2$ peak of the different samples. The XPS spectra of $\mathrm{V} 2 \mathrm{p} 3 / 2$ can be deconvoluted into two peaks assigned to the $\mathrm{V}^{5+}$ and $\mathrm{V}^{4+}$ species, which were observed at $517.4 \mathrm{eV}$ and $516.3 \mathrm{eV}$, respectively. The ratio of $\mathrm{V}^{+} /\left(\mathrm{V}^{5+}+\mathrm{V}^{4+}\right)$ was determined through the calculation of the integrated peak areas of $\mathrm{V}^{5+}$ and $\mathrm{V}^{4+}$ species. The oxidation process of organic molecules on the catalyst surface is associated with the reduction of $\mathrm{V}^{5+}$ to $\mathrm{V}^{4+}$. Therefore, a higher $\mathrm{V}^{5+}$ species ratio is considered to be beneficial to the conversion of 1,2-DCBz and dioxins on the catalyst surface. As the Table S2 shows, the $\mathrm{V}^{5+}$ ratio of VTi-MC2 is $80 \%$, which is higher than that of VTi-WI (77\%) and VTi-SG (72\%). It is well known that larger specific surface area is benefits in improving the dispersion of the active component VOx species, increasing the probability of contact between vanadium and oxygen in the atmosphere, and thus facilitate the oxidation of vanadium to higher valences. Although the specific surface area of VTi-SG $\left(133 \mathrm{~m}^{2} / \mathrm{g}\right)$ is much larger than that of the other two catalysts, the $\mathrm{V}^{5+}$ ratio $(72 \%)$ of VTi-SG catalyst is the lowest. This may because the ink-bottle shaped pores are not conducive to the diffusion of oxygen in the pores of the catalyst and hinder the sufficient contact of vanadium species and oxygen on the catalyst surface. 
Figure 2 (b) shows that the 01 s peak of various $\mathrm{VO}_{\mathrm{x}} / \mathrm{TiO}_{2}$ samples prepared by different methods, which could be divided into two bands. The sub-bands at 531.3-531.9 eV are assigned to the surface adsorbed oxygen (denoted as $\mathrm{O}_{\mathrm{a}}$ ), and the sub-bands at 529.3-530.0 eV are attributed to the lattice oxygen (denoted as $\mathrm{O}_{\beta}$ ) (Chen et al. 2009). It is clearly showed that the binding energy of 01s peak for VTi-MC2 was lower than that of the other two catalysts about $0.2 \mathrm{eV}$. On the other hand, VTi-MC2 presents a higher $\mathrm{O}_{\mathrm{a}}$ ratio of $18 \%$ than those of VTi-SG (13\%) and VTi-WI (9\%). As it is well know that the relatively higher concentration of surface adsorbed oxygen is benefical for the high oxidation activity (Kang et al. 2007, Zhang et al. 2015). It hints that the interaction between oxygen species and metal-dopant on VTi-MC catalyst surface is strengthened through the mechanochemical process. This leads to more surface oxygen vacancy and the increasing amount of chemisorbed oxygen species. In the process of mechanical milling, the energy generated by the friction and collision of steel balls can precipitate the surface lattice oxygen and produce a large number of oxygen vacancies (Ralphs et al. 2013). Then, oxygen is adsorbed on the surface oxygen vacancy and dissociated to form surface chemically adsorbed oxygen, which could effectively improve the catalytic oxidation activity.

Furthermore, it was found that in the case of VTi-MC, more $\mathrm{V}^{5+}$ species and $\mathrm{O}_{\mathrm{a}}$ species were present in the crystalline $\mathrm{V}_{2} \mathrm{O}_{5}$ species formed with increasing milling time. The details are shown in Figure S5. This may be due to the prolonged ball milling time, which helps the vanadium oxide contacts with air, therefore, it is easier to be oxidized to high valence vanadium (Zhao et al. 2009).

To gain further insight into the redox ability of various catalysts, $\mathrm{H}_{2}$-TPR experiments were then conducted, and the results are shown in Fig. 3. The significantly large hydrogen consumption peaks centered at around $450 \sim 470{ }^{\circ} \mathrm{C}$ were assigned to the reduction of $\mathrm{VO}_{\mathrm{X}}$ from $\mathrm{V}^{5+} \mathrm{Ox}$ to $\mathrm{V}^{4+} \mathrm{Ox}$ (Wang et al. 2018). The relatively weak peaks centered at around $650 \sim 690{ }^{\circ} \mathrm{C}$ were belonged to the reduction of carbon deposited on the catalyst surface, which was from the residence of organic solvent during the catalyst preparation process. Generally, monomeric or highly dispersed $\mathrm{VO}_{\mathrm{x}}$ display reduction peaks at lower temperatures than polymeric or bulk-like $\mathrm{VO}_{\mathrm{x}}$ (Kwon et al. 2013). It is remarkable that, the hydrogen consumption peak of VTi-MC2 was about $20^{\circ} \mathrm{C}$ lower than that of VTi-WI, thus demonstrating that the redox ability of VTi-MC2 was stronger than that of VTi-WI. Furthermore, the $\mathrm{VO}_{\mathrm{x}}$ species of VTi-MC2 are expected to distribute more uniformly on the catalyst surface according to its notably narrower reduction peak.

Figure 3(B) shows the $\mathrm{H}_{2}$-TPR relusts of VTi-MC catalysts with different ball-milling times. The position of the maximum reducing temperature decreased to lower temperature as the ball-milling time increased. This may be due to the crystallite $\mathrm{V}_{2} \mathrm{O}_{5}$ species transformed into monomeric species during ball milling process according to the interaction between $\mathrm{V}_{2} \mathrm{O}_{5}$ and $\mathrm{TiO}_{2}$. According to the previous XRD results, excessively long ball-milling time caused the collapse the $\mathrm{TiO}_{2}$ crystal structure. Therefore, this reduced the dispersibility of $\mathrm{VO}_{\mathrm{x}}$ species, which significantly reduces the total acid content of the catalyst (Table 1). 
On the basis of the above comprehensive analysis, compared with the $\mathrm{VO}_{\mathrm{x}} / \mathrm{TiO}_{2}$ catalysts prepared by the traditional method, the VTi-MC catalyst prepared by the ball-milling method presents stronger redox ability, more $\mathrm{V}^{5+}$ species and surface adsorbed oxygen species. This, plays an important role on the degradation of dichlorobenzene at low temperatures. Thus, it is expected that VTi-MC can serve as a promising catalyst.

\subsection{Catalyst activity}

The high toxicity and very low volatility of PCDD/PCDFs prevent a extensive study of their catalytic degradation removal characteristics. Therefore, 1, 2-dichlorobenzene (1,2-DCBz) was used as a model to investigate the catalytic activities of various $\mathrm{VO}_{\mathrm{x}} / \mathrm{TiO}_{2}$ catalysts in this study firstly.

Figure 4(A) presented the 1,2-DCBz removal efficiency of various catalysts as a function of temperature. In general, the removal efficiency increased with increasing temperature at the range of $150-300{ }^{\circ} \mathrm{C}$ for all the catalysts. Especially, the VTi-MC presents the highest removal efficiency at temperatures lower than $200^{\circ} \mathrm{C}$, which suggests the catalyst prepared by ball-milling method has better low-temperature activity. However, in the range of $200-300^{\circ} \mathrm{C}$, the activity of VTi-MC and VTi-WI catalysts was similar, and the activity of VTi-SG catalyst was the lowest.

As is well known, the higher $\mathrm{V}^{5+}$ species and surface adsorbed oxygen content are the key factor for the high activity. Thus, combined with the XPS characterization results, the highest activity of VTi-MC is ascribed to the highest $\mathrm{V}^{5+}$ and $\mathrm{O}_{\mathrm{a}}$ content. This is owing to the energy generated during the ball milling process will cause some damage to the $\mathrm{TiO}_{2}$ crystal and promote the formation of crystal defects. These crystal defects can provide binding sites for $\mathrm{VO}_{\mathrm{x}}$ species and promote the dispersion of $\mathrm{VO}_{\mathrm{x}}$. Moreover, in the process of ball milling, the energy generated by friction and collision of steel balls can precipitate surface lattice oxygen and produce a large number of oxygen vacancies. And thus, the oxygen in the air can dissociate and adsorb on the surface oxygen vacancy to form surface chemically adsorbed oxygen.

In order to research the influence of ball milling parameters on the catalytic activity, we compared a series of VTi-MC catalysts prepared with different ball-milling time. In Fig. 4 (B), the removal efficiency of 1,2$\mathrm{DCBz}$ increased with the increase of temperature. Firstly, with the increase of ball milling time from $0.5 \mathrm{~h}$ to $2 \mathrm{~h}$, the removal efficiency gradually increased, and that of 1,2-DCBz of VTi-MC2 can reached $85 \%$ at $150^{\circ} \mathrm{C}$. However, as the milling time continued to increase, the removal efficiency of 1,2-dichlorobenzene showed a downward trend (Figure S6). According to the characterization results, even though the heat generated during the ball milling process causes the formation of $\mathrm{TiO}_{2}$ crystal defects, which can be used as additional binding sites for $\mathrm{VO}_{\mathrm{x}}$, while extensive long ball milling time will lead to the collapse of $\mathrm{TiO}_{2}$ crystal structure and seriously damage the pore structure of the catalyst. Meanwhile, the specific surface area and the amount of acid on the surface of the catalyst increased at first and then decreased with the increase of ball milling time. Accordingly, the ball milling method can be used to control the physicochemical properties of $\mathrm{VO}_{\mathrm{x}} / \mathrm{TiO}_{2}$ through adjusting the milling parameters, which can in turn improve the catalytic degradation performance. 
The long-term reaction was conducted at $150^{\circ} \mathrm{C}$ to test the catalysts stability of VTi-MC2. As shown in Figure S7, the catalytic activity of VTi-MC2 maintained its high 1,2-DCBz removal efficiency during the entire stability test within $420 \mathrm{~min}$. As shown in Figure S8, according to the characterization results (including $\mathrm{N}_{2}$ adsorption and desorption, XRD, XPS and $\mathrm{H}_{2}$-TPR), the physical and chemical properties of the catalyst have no obvious changes before and after application. This implies that the physical and chemical properties of the catalyst are relatively stable. The results indicate that VTi-MC2 is a promising catalyst for practical application.

\section{Reaction condition: $\mathrm{SV}=20,000 \mathrm{~h}^{-1}$, inlet PCDD/Fs $=3.20 \mathrm{ng} \mathrm{TEQ} / \mathrm{Nm}^{3}, 1 \mathrm{~h}$.}

Based on the above results, we adopted the best VTi-MC2 catalyst for the catalytic degradation of gaseous PCDD/Fs. The distributions of the catalytic removal efficiency, degradation efficiency and adsorption efficiency of dioxins at different temperatures were investigated.

As shown in Fig. 5 (A), the removal efficiency of gaseous PCDD/Fs on VTi-MC2 catalyst can reach more than $97 \%$ in the temperature range of $160-300{ }^{\circ} \mathrm{C}$. This is mainly due to the well-developed pore structure and strong surface acidity of the VTi-MC2 catalyst. This catalyst can successfully adsorb almost all the toxic dioxins in flue gas to the surface of the catalyst after passing through the catalyst powder fixed bed. The pore size distribution of the $\mathrm{VO}_{\mathrm{x}} / \mathrm{TiO}_{2}$ catalyst prepared by ball milling is concentrated, and the pore volume in the range of $2-5 \mathrm{~nm}$ is very large. This pore size is close to the size of dioxins (1-2nm), which is beneficial to the adsorption of dioxins. Moreover, the catalyst also has strong acidity, indicating that the adsorption capacity of the catalyst is strong.

At a low temperature of $160{ }^{\circ} \mathrm{C}$, the adsorption efficiency of the PCDD/Fs total toxic equivalent is $84 \%$, which is much greater than the degradation efficiency (14\%). With elevating the temperatures, the residual PCDD/Fs on the surface of the catalyst decreased, while the degradation efficiency of PCDD/Fs increased. On the one hand, when the temperature is low, the proportion of activated PCDD/Fs molecules is small. On the other hand, the redox ability of the catalyst is weak at low temperature. Therefore, when the reaction temperature is low $\left(160^{\circ} \mathrm{C}\right)$, the removal of PCDD/Fs in flue gas mainly depends on the adsorption of catalyst. With the increase of temperature, the proportion of dioxin activated molecules increases as well as the molecular mass transfer, pore diffusion rate and redox ability of the catalyst. The PCDD/Fs molecules that collide with the catalyst surface are more easily oxidized and decomposed. Therefore, the degradation efficiency of PCDD/Fs is improved. It is noteworthy that the catalytic degradation of PCDD/Fs is about $51 \%$ at $180^{\circ} \mathrm{C}$, which is higher than those reported research(GallastegiVilla et al. 2020, Wang et al. 2016). This confirms that VTi-MC is a potential catalyst for PCCD/Fs degradation at low temperatures.

As shown in Fig. 5 (B), the degradation efficiency of PCDDs is higher than that of PCDFs. This signifies that PCDDs are more easily to be degraded on the surface of $\mathrm{VO}_{\mathrm{x}} / \mathrm{TiO}_{2}$ catalyst than PCDFs. This may be due to that the PCDFs in the source have more highly chlorinated dioxin congeners. This can produce more lowly chlorinated congeners with higher toxicity through dechlorination processes, resulting in a 
higher concentration of PCDFs I-TEQ. In addition, the catalytic removal and degradation efficiency of semi-volatile organic compounds are related to the volatility and redox ability of the compound.(Chang et al. 2008) The increase of the chlorination value will not only increase the molecular redox potential of organic compounds, but also increase the molecular weight and reduce the volatility. Compared with the low chlorinated dioxins, the higher chlorinated dioxins have higher redox potential, so they are more stable and not easily oxidized and decomposed.

It can be seen from Fig. 6 that the relationship between the degradation efficiency of 17 PCDD/Fs congeners and the number of chlorine substitutions is similar under different temperatures. There was not a linear correlation between the degradation efficiency of PCDD congeners and the number of chlorination. When the chlorination value increased from tetrachlorination to hexachlorination, the degradation efficiency of PCDD congeners increased. Meanwhile, when the chlorination numbers continued to increase to octachlorination, the degradation efficiency of PCDDs congeners decreased. The change of the catalytic degradation efficiency of PCDFs congeners with the number of chlorination is similar to that of PCDDs congeners. Firstly, it increases with the increase of the chlorination value, but when the chlorination value increases to octachloride, the removal efficiency decreases. The volatility and redox potential of PCDD/Fs congeners have certain effects on its degradation efficiency. When the number of chlorination is lower than that of hexachloro, the volatility is the dominant factor. With the increase of the number of chlorination, the molecular weight of PCDD/Fs congeners increases and the volatility decreases. It is easier to adsorb to the surface of the catalyst to participate in the reaction, and also increases the degradation efficiency. When the chlorination number is higher than hexachlorination, the redox potential is dominant, with the increase of the chlorination number, the redox potential of PCDD/Fs congeners increases, and the difficulty of oxidation decomposition increases. Therefore, the degradation efficiency decreases with the increase of the chlorination value. In addition, the dechlorination of high chlorinated PCDD/Fs congeners to produce low chlorinated PCDD/Fs congeners is also one of the reasons for the low degradation efficiency of low chlorinated PCDD/Fs congeners.

\section{Conclusion}

In this study, various $\mathrm{VO}_{\mathrm{x}} / \mathrm{TiO}_{2}$ catalysts were prepared by the sol-gel method, wet impregnation method and ball-milling method. It is found that the VTi-MC2 synthesized by the ball-milling method exhibits a higher activity for 1,2-DCBz removal at low temperatures than that of VTi-SG and VTi-WI. Furthermore, the VTi-MC2 displays a high 1,2-DCBz removal efficiency (> 80\%) during the stability test within 420 min at relatively low temperatures $\left(150^{\circ} \mathrm{C}\right)$. Compared with the other two $\mathrm{VO}_{\mathrm{x}} / \mathrm{TiO}_{2}$ catalysts prepared by sol-gel method, wet impregnation method, comprehensive characterizations showed that, VTi-MC2 prepared by ball-milling method had better VOx species dispersion. It also possesses the highest $\mathrm{V}^{5+}$ species and surface adsorbed oxygen content, which are the key contributing factor to the higher 1,2-DCBz removal efficiency. During the process of ball milling, the energy produced by friction and collision of steel balls can increase the probability of contact between vanadium and oxygen in the atmosphere. This facilitates the oxidation of vanadium, and can also precipitate lattice oxygen on the surface and generate a large 
number of oxygen vacancies, resulting in high chemisorbed oxygen content on the surface of VTi-MC catalyst. Accordingly, the ball milling method can be used to control the physicochemical properties of $\mathrm{VO}_{\mathrm{x}} / \mathrm{TiO}_{2}$ by adjusting the milling parameters, and the optimum ball-milling time is $2 \mathrm{~h}$.

In addition, in the temperature range of $160 \sim 300^{\circ} \mathrm{C}$, the removal efficiency of gas phase PCDD/Fs catalyzed by VTi-MC2 can reach more than $97 \%$. This is mainly due to the well-developed pore structure and strong surface acidity of VTi-MC2 catalyst prepared by ball milling. This catalyst can successfully adsorb almost all toxic dioxins in the flue gas to the catalyst surface. Although, at relatively low temperature $\left(<200^{\circ} \mathrm{C}\right)$, the adsorption efficiency of the dioxins is much greater than the degradation efficiency. It is remarkable that with the increase of temperature, the degradation efficiency of dioxins is improved.

Therefore, we will continue to develop high-efficiency catalysts for low-temperature degradation of dioxin in the following work. In general, the ball-milling strategy reported here provides a means for seeking more efficiency catalysts used for low-temperature degradation of various trace organic pollutants.

\section{Declarations}

\section{Authors' contributions}

Minghui Tang: conceptualization, investigation, and writing the original draft preparation. Qinlin Ye, Cuicui Du: investigation, methodology, data curation. Chengetai Portia Makwarimba, Yao He: reviewing, editing. Shengyong Lu, Yaqi Peng: investigation, conceptualization.

\section{Availability of data and materials}

All data and materials generated or analyzed during this study were included in this published article and its supplementary information files.

\section{Acknowledgments}

This work was financially supported by the National Natural Science Foundation of China (No. 52006191), the Natural Science Foundation of Zhejiang Province (No. LY21E060007), the National Natural Science Foundation of China (No. 51976192) and the Fundamental Research Funds for the Central Universities.

\section{Compliance with ethical standards}

Competing interests The authors declare that they have no competing interests.

Ethical approval The paper is a conceptualization and analysis of the published literature on the topic. No human subjects or animals were used in this paper.

Consent to participate Not applicable.

Consent to publish Not applicable. 


\section{References}

Baláž P, Achimovičová M, Baláž M, Billik P, Cherkezova-Zheleva Z, Criado JM, Delogu F, Dutková E, Gaffet E, Gotor FJ, Kumar R, Mitov I, Rojac T, Senna M, Streletskii A, Wieczorek-Ciurowa K (2013): Hallmarks of mechanochemistry: from nanoparticles to technology. Chemical Society Reviews 42, 7571-7637

Bertinchamps F, Treinen M, Blangenois N, Mariage E, Gaigneaux EM (2005): Positive effect of NOx on the performances of $\mathrm{VOx} / \mathrm{TiO} 2$-based catalysts in the total oxidation abatement of chlorobenzene. Journal of Catalysis 230, 493-498

Bertinchamps F, Grégoire C, Gaigneaux EM (2006): Systematic investigation of supported transition metal oxide based formulations for the catalytic oxidative elimination of (chloro)-aromatics: Part l: Identification of the optimal main active phases and supports. Applied Catalysis B: Environmental 66, 1-9

Chang MB, Chi KH, Chang SH, Yeh JW (2007): Destruction of PCDD/Fs by SCR from flue gases of municipal waste incinerator and metal smelting plant. Chemosphere $66,1114-1122$

Chang SH, Yeh JW, Chein HM, Hsu LY, Chi KH, Chang MB (2008): PCDD/F Adsorption and Destruction in the Flue Gas Streams of MWI and MSP via $\mathrm{Cu}$ and Fe Catalysts Supported on Carbon. Environmental Science \& Technology 42, 5727-5733

Chen L, Li J, Ge M (2009): Promotional Effect of Ce-doped V205-W03/TiO2 with Low Vanadium Loadings for Selective Catalytic Reduction of NOx by NH3. The Journal of Physical Chemistry C 113, 21177-21184

Chin S, Jurng J, Lee J-H, Moon S-J (2009): Catalytic conversion of 1,2-dichlorobenzene using V205/TiO2 catalysts by a thermal decomposition process. Chemosphere 75, 1206-1209

Cieplik MK, De Jong V, Bozovič J, Liljelind P, Marklund S, Louw R (2006): Formation of Dioxins from Combustion Micropollutants over MSWI Fly Ash. Environmental Science \& Technology 40, 1263-1269

Coste S, Bertrand G, Coddet C, Gaffet E, Hahn H, Sieger H (2007): High-energy ball milling of Al2O3-TiO2 powders. Journal of Alloys and Compounds 434-435, 489-492

Danielis M, Colussi S, de Leitenburg C, Soler L, Llorca J, Trovarelli A (2019): The effect of milling parameters on the mechanochemical synthesis of $\mathrm{Pd}-\mathrm{CeO} 2$ methane oxidation catalysts. Catalysis Science \& Technology 9, 4232-4238

Debecker DP, Delaigle R, Hung PC, Buekens A, Gaigneaux EM, Chang MB (2011): Evaluation of PCDD/F oxidation catalysts: Confronting studies on model molecules with tests on PCDD/F-containing gas stream. Chemosphere 82, 1337-1342

Delaigle R, Debecker DP, Bertinchamps F, Gaigneaux EM (2009a): Revisiting the Behaviour of VanadiaBased Catalysts in the Abatement of (Chloro)-Aromatic Pollutants: Towards an Integrated Understanding. 
Delaigle R, Debecker DP, Bertinchamps F, Gaigneaux EM (2009b): Revisiting the Behaviour of VanadiaBased Catalysts in the Abatement of (Chloro)-Aromatic Pollutants: Towards an Integrated Understanding. Topics in Catalysis 52, 501-516

Du C, Ji L, Peng Y, Tang M, Cao X, Lu S (2018a): Catalytic decomposition of PCDD/Fs on a V205WO3/nano-TiO2 catalyst: effect of NaCl. Environmental Science and Pollution Research 25, 15474-15483

Du C, Lu S, Wang Q, Buekens AG, Ni M, Debecker DP (2018b): A review on catalytic oxidation of chloroaromatics from flue gas. Chemical Engineering Journal 334, 519-544

Everaert K, Baeyens J (2002): The formation and emission of dioxins in large scale thermal processes. Chemosphere $46,439-448$

Gallastegi-Villa M, Aranzabal A, González-Marcos JA, González-Velasco JR (2017): Tailoring dual redoxacid functionalities in VOx/TiO2/ZSM5 catalyst for simultaneous abatement of PCDD/Fs and NOx from municipal solid waste incineration. Applied Catalysis B: Environmental 205, 310-318

Gallastegi-Villa M, Aranzabal A, González-Marcos MP, Markaide-Aiastui BA, González-Marcos JA, González-Velasco JR (2020): Effect of vanadia loading on acidic and redox properties of VOx/TiO2 for the simultaneous abatement of PCDD/Fs and NOx. Journal of Industrial and Engineering Chemistry 81, $440-450$

Gannoun C, Turki A, Kochkar H, Delaigle R, Eloy P, Ghorbel A, Gaigneaux EM (2014): Elaboration and characterization of sulfated and unsulfated V205/TiO2 nanotubes catalysts for chlorobenzene total oxidation. Applied Catalysis B: Environmental 147, 58-64

James SL, Adams CJ, Bolm C, Braga D, Collier P, Friščić T, Grepioni F, Harris KDM, Hyett G, Jones W, Krebs A, Mack J, Maini L, Orpen AG, Parkin IP, Shearouse WC, Steed JW, Waddell DC (2012): Mechanochemistry: opportunities for new and cleaner synthesis. Chemical Society Reviews 41, 413-447

1. S. W. SING DHE, R. A. W. HAUL, L. MOSCOU, , R. A. PIEROTTI JR, T. SIEMIENIEWSKA (1985): Reporting physisorption data for gas/soild systems with Special Reference to the Determination of Surface Area and Porosity. Pure \& Appl. Chem. 57, 603-619

Kang M, Park ED, Kim JM, Yie JE (2007): Manganese oxide catalysts for NOx reduction with NH3 at low temperatures. Applied Catalysis A: General 327, 261-269

Kwon DW, Park KH, Hong SC (2013): The influence on SCR activity of the atomic structure of V205/TiO2 catalysts prepared by a mechanochemical method. Applied Catalysis A: General 451, 227-235

McKay G (2002): Dioxin characterisation, formation and minimisation during municipal solid waste (MSW) incineration: review. Chemical Engineering Journal 86, 343-368 
Muñoz-Batista MJ, Rodriguez-Padron D, Puente-Santiago AR, Luque R (2018): Mechanochemistry: Toward Sustainable Design of Advanced Nanomaterials for Electrochemical Energy Storage and Catalytic Applications. ACS Sustainable Chemistry \& Engineering 6, 9530-9544

Oh J-E, Gullett B, Ryan S, Touati A (2021): Chlorobenzenes, chlorophenols, PAHs and low chlorinated dioxin/furan as post-boiler toxicity indicators in municipal solid waste incinerators. Organohalogen Compounds 66: 777-782.

Ralphs K, Hardacre C, James SL (2013): Application of heterogeneous catalysts prepared by mechanochemical synthesis. Chem Soc Rev 42, 7701-18

Wang J, Wang X, Liu X, Zhu T, Guo Y, Qi H (2015): Catalytic oxidation of chlorinated benzenes over V205/TiO2 catalysts: The effects of chlorine substituents. Catalysis Today 241, 92-99

Wang Q, Hung PC, Lu S, Chang MB (2016): Catalytic decomposition of gaseous PCDD/Fs over V2O5/TiO2-CNTs catalyst: Effect of NO and NH3 addition. Chemosphere 159, 132-137

Wang Q, Tang M, Peng Y, Du C, Lu S (2018): Ozone assisted oxidation of gaseous PCDD/Fs over CNTscontaining composite catalysts at low temperature. Chemosphere 199, 502-509

Xujian Z, Xiaodong L, Xianhua M, Shasha J, Mingjiang N, Kefa C (2014): Adsorption of Polychlorinated Dibenzo-p-Dioxins and Dibenzofurans Vapors on Activated Carbon. Environmental Engineering Science $31,664-670$

Yang RT, Long RQ, Padin J, Takahashi A, Takahashi T (1999): Adsorbents for Dioxins: A New Technique for Sorbent Screening for Low-Volatile Organics. Industrial \& Engineering Chemistry Research 38, 27262731

Yang Y, Zhang S, Wang S, Zhang K, Wang H, Huang J, Deng S, Wang B, Wang Y, Yu G (2015): Ball Milling Synthesized MnOx as Highly Active Catalyst for Gaseous POPs Removal: Significance of Mechanochemically Induced Oxygen Vacancies. Environmental Science \& Technology 49, 4473-4480

Yu M-f, Lin X-q, Li X-d, Yan M, Prabowo B, Li W-w, Chen T, Yan J-h (2016): Catalytic destruction of PCDD/Fs over vanadium oxide-based catalysts. Environmental Science and Pollution Research 23, 16249-16258

Zhang S, Huang J, Yang Y, Li Y, Wang B, Wang Y, Deng S, Yu G (2015): Rapid mechanochemical synthesis of VOx/TiO2 as highly active catalyst for HCB removal. Chemosphere 141, 197-204

Zhao H, Bennici S, Shen J, Auroux A (2009): The influence of the preparation method on the structural, acidic and redox properties of V2O5-TiO2/SO42- catalysts. Applied Catalysis a-General 356, 121-128

\section{Figures}



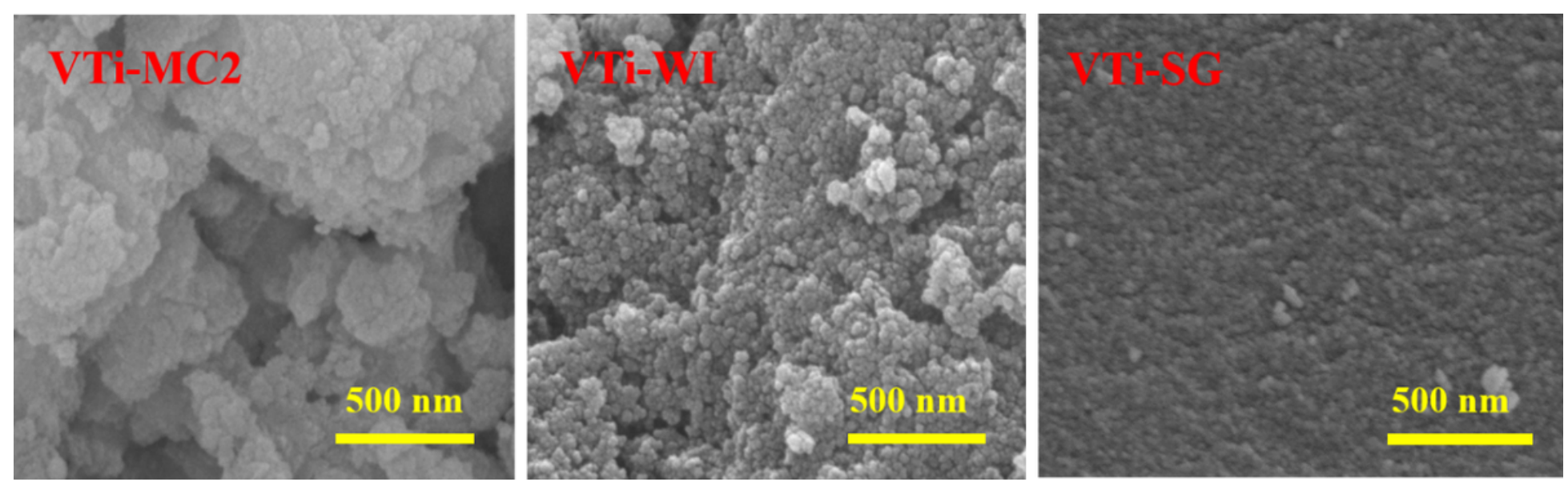

Figure 1

SEM images of various VOX/TiO2 catalyst samples
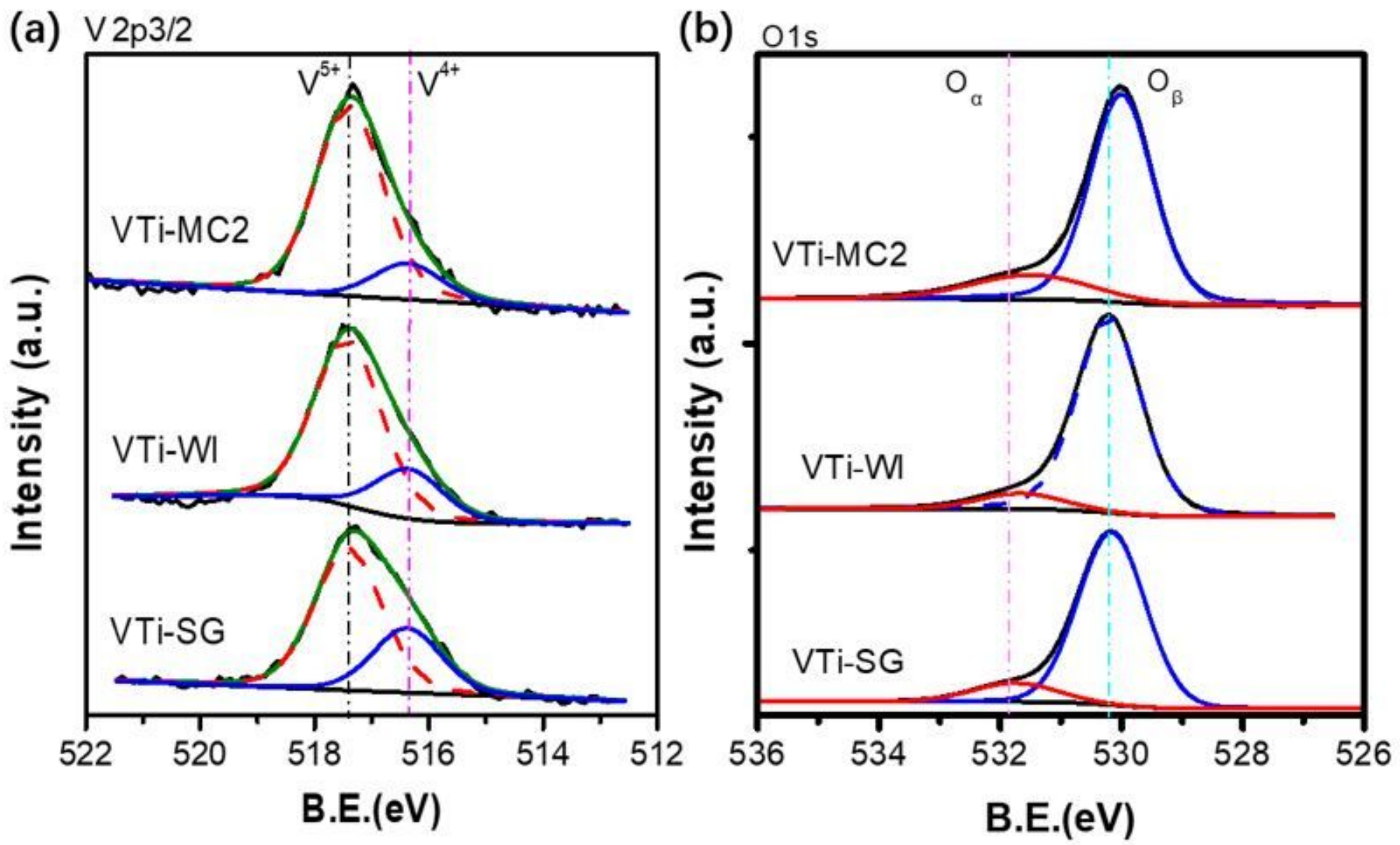

Figure 2

XPS patterns of various VOx/TiO2 samples (a)V 2p 3/2, (b) 01s. 

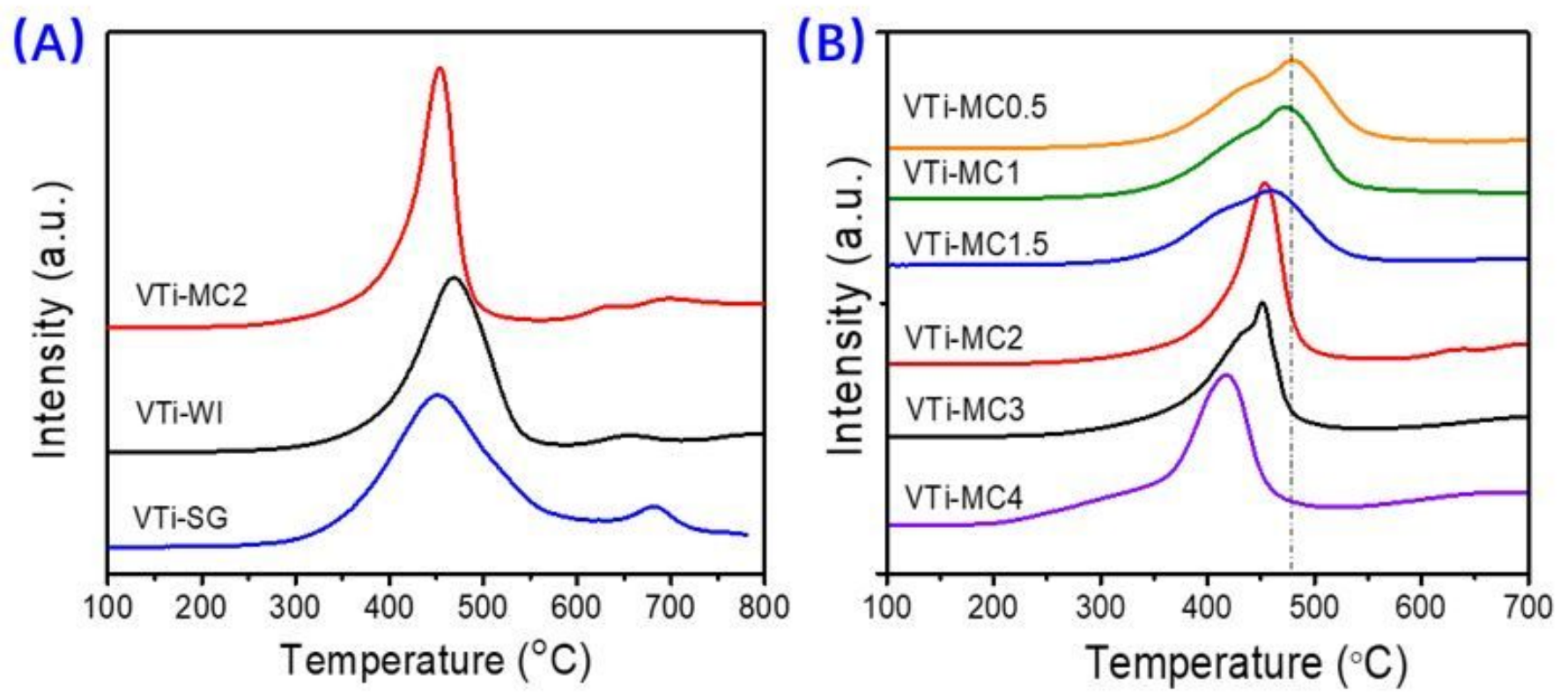

Figure 3

H2-TPR profiles of (A) various VOx/TiO2 samples prepared by different methods, and (B) VTi-MCt catalysts.
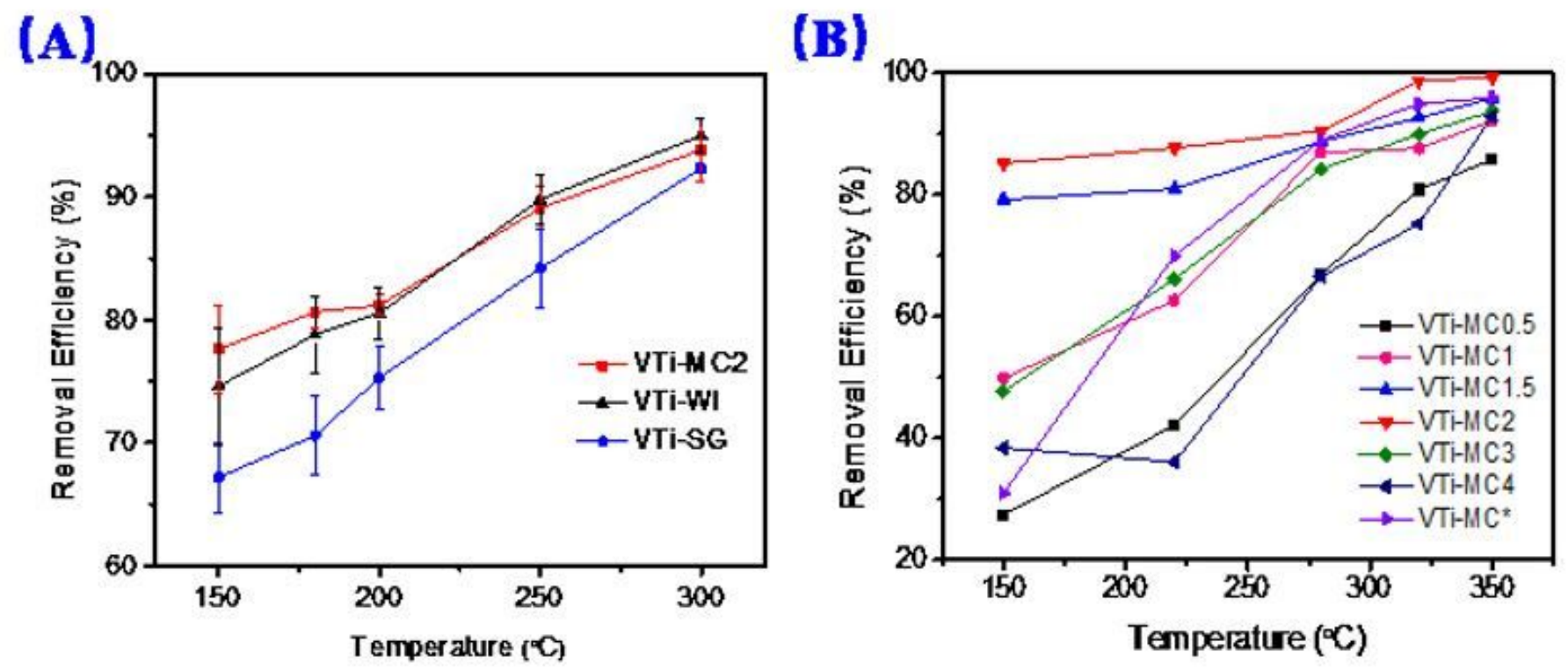

Figure 4

(A) The 1,2-DCBz removal efficiency of various VOx/TiO2 samples (7000 h-1, 228ppm); (B) The 1,2-DCBz removal efficiency of various $\mathrm{VOx} / \mathrm{TiO} 2$ samples with different Ball milling time and different precursor (7000 h-1, 117 ppm). 

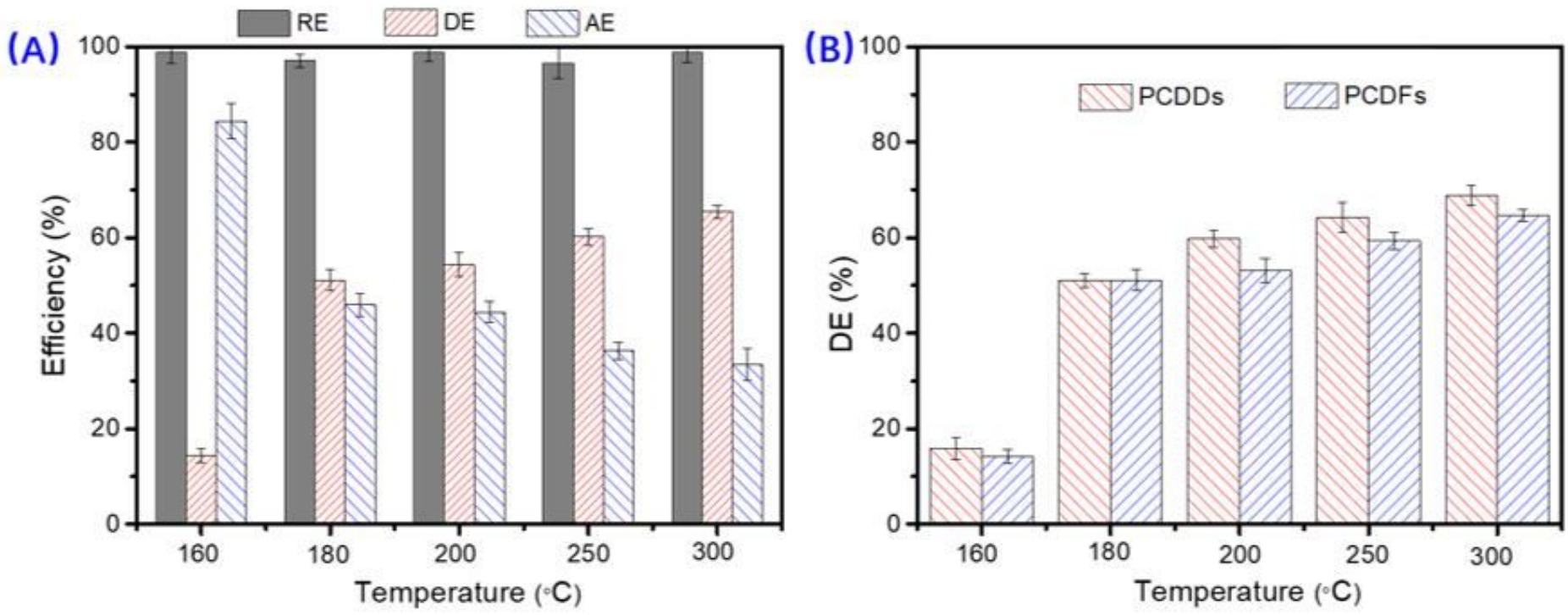

Figure 5

(A) The PCDD/Fs Removal Efficiency (RE), Degradation Efficiency (DE) and Adsorption Efficiency (AE) of VTi-MC2 at different temperature. (B) The total toxic equivalent degradation efficiency (DE) of PCDDs and PCDFs at different temperature. Reaction condition: $S V=20,000 \mathrm{~h}-1$, inlet PCDD/Fs $=3.20 \mathrm{ng} T E Q / \mathrm{Nm} 3$, $1 \mathrm{~h}$.
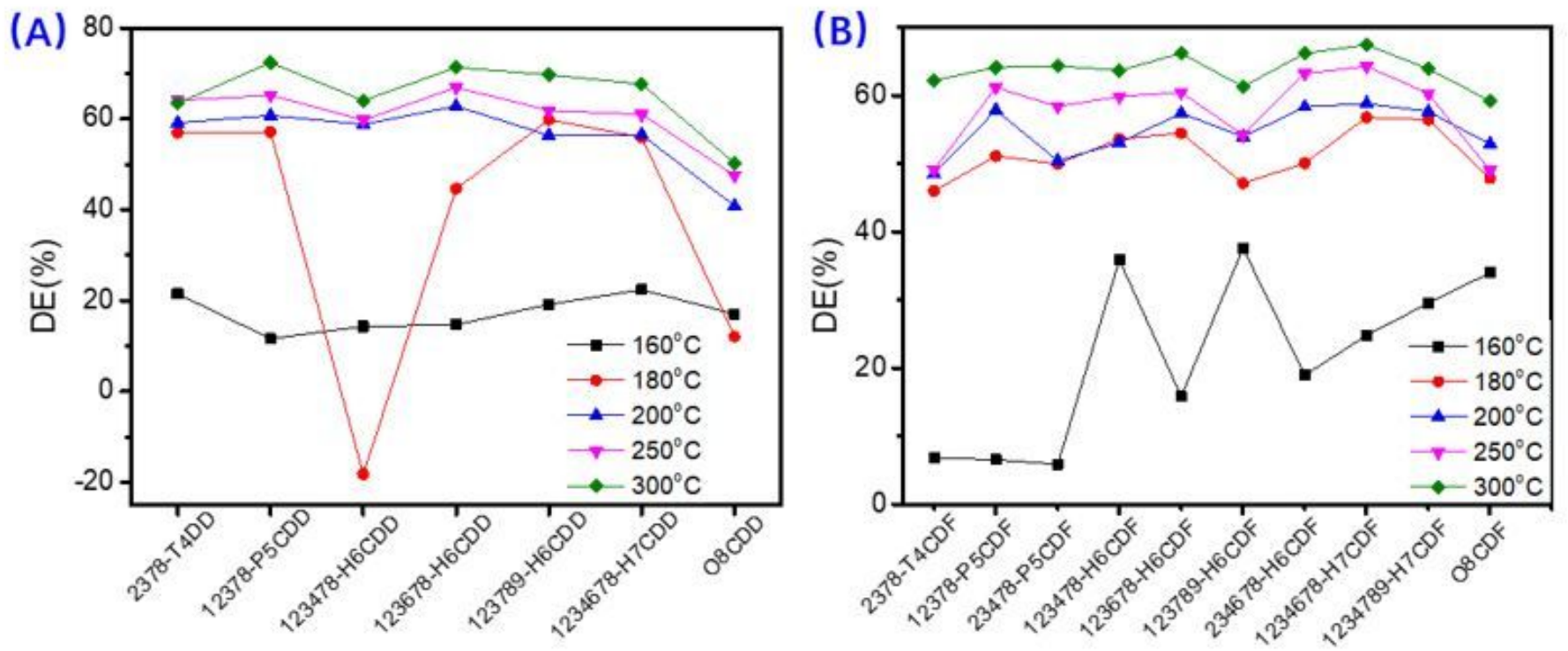

Figure 6

The degradation efficiency of 17 PCDD/Fs homologues at different temperature ( $S V=20,000 \mathrm{~h}-1$, inlet $\mathrm{PCDD} / \mathrm{Fs}=3.20 \mathrm{ng} \mathrm{TEQ} / \mathrm{Nm} 3$, reaction time $=1 \mathrm{~h} \rrbracket$

\section{Supplementary Files}


This is a list of supplementary files associated with this preprint. Click to download.

- SI0425.docx 